\title{
Affordability of and Access to Information About Health Insurance Among Immigrant and Non- Immigrant Residents After Massachusetts Health Reform
}

\section{Citation}

Kang, Ye jin. 2018. Affordability of and Access to Information About Health Insurance Among Immigrant and Non-Immigrant Residents After Massachusetts Health Reform. Doctoral dissertation, Harvard Medical School.

\section{Permanent link}

http://nrs.harvard.edu/urn-3:HUL.InstRepos:41973456

\section{Terms of Use}

This article was downloaded from Harvard University's DASH repository, and is made available under the terms and conditions applicable to Other Posted Material, as set forth at http:// nrs.harvard.edu/urn-3:HUL.InstRepos:dash.current.terms-of-use\#LAA

\section{Share Your Story}

The Harvard community has made this article openly available.

Please share how this access benefits you. Submit a story.

\section{Accessibility}




\title{
Scholarly Report submitted in partial fulfillment of the MD Degree at Harvard Medical School
}

\section{Date: 1 Mar 2018}

\section{Student Name: Ye jin Kang, MSc Medical Anthropology, Master of Public Policy}

Scholarly Report Title:Affordability of and Access to Information About Health Insurance Among Immigrant and Non-immigrant Residents After Massachusetts Health Reform

\section{Mentor Name(s) and Affiliations:}

Leah Zallman, MD and Danny McCormick MD ; Cambridge Health Alliance, Cambridge USA ; Institute for Community Health, Malden USA

\begin{abstract}
:
Immigrants' perceptions of affordability of insurance and knowledge of insurance after health reform are unknown. We conducted face-to-face surveys with a convenience sample of 1124 patients in three Massachusetts safety net Emergency Departments after the Massachusetts health reform (August 2013-January 2014), comparing immigrants and non-immigrants. Immigrants, as compared to non-immigrants, reported more concern about paying premiums ( 30 vs. $11 \%, p=0.0003$ ) and about affording the current ED visit (38 vs. $22 \%, p<0.0001$ ). Immigrants were also less likely to report having unpaid medical bills ( 24 vs. $32 \%, p=0.0079$ ), however this difference was not present among those with any hospitalization in the past year. Insured immigrants were less likely to know copayment amounts (57 vs. $71 \%, p=0.0018$ ). Immigrants were more likely to report that signing up for insurance would be easier with fewer plans (53 vs. $34 \%, p=0.0443$ ) and to lack information about insurance in their primary language (31 vs. $1 \%, p<0.0001$ ) when applying for insurance. Immigrants who sought insurance information via websites or helplines were more likely to find that information useful than non-immigrants (100 vs. $92 \%, p=0.0339$ ). Immigrants seeking care in safety net emergency departments had mixed experiences with affordability of and knowledge about insurance after Massachusetts health reform, raising concern about potential disparities under the Affordable Care Act that is based on the MA reform.
\end{abstract}

The final publication is available at Springer via http://dx.doi.org/10.1007/s10903-016-0479-y.". 


\section{Description of Contribution to HMS Scholarly Project}

As a student who worked on this manuscript under Dr. Leah Zallman since the Summer of 2014, I contributed heavily to the production of this paper, in the components of data analysis, manuscript writing, and editing. I participated heavily in the discussions for moving the project forward, contributing heavily to the brainstorming, analytical and writing process in the meantime. The process was enriching for its teaching methodology into the scientific process.

To start with, I delved into the literature and learned more about immigration health in the United States and the racial disparities present. Upon doing this, I received a solid understanding of the literature that would allow me to contribute to the introduction, analyses, and discussion in the paper. I learned an important quantitative skill set in learning how to write and manipulate SAS computer code and to interpret different kinds of statistics for the paper ( Chi-square analyses and logistic regression analyses), and I applied this knowledge to the development of this manuscript.

My contribution was especially heavy in the part of writing or editing a large amount of the SAS computer code, to reflect what our team wanted in the analyses and discussion. I went to great lengths to double check that the SAS code was reflective of what was written in the survey questions. I analyzed the results that were generated in the SAS code, and contributed to the discussions in the paper through the culmination of insight from literature, survey data and subsequent analyses.

Throughout the years, we would exchange drafts and ideas for this project, and I was able to focus heavily on this project in April 2016 and in Summer of 2016. I was included in all aspects of the writing process, and I had a very enriching experience as a result. We finally concluded the project and was able to get it published successfully in the Journal of Immigrant and Minority Health. Dr. Leah Zallman supervised the different components of the research process, providing feedback and direction throughout the process as necessary, and Dr. Danny McCormick provided detailed insight and feedback on several versions of the paper throughout. Both were extremely responsive and supportive throughout the research process from beginning to end. 
Link to publication https://link.springer.com/article/10.1007\%2Fs10903-016-0479-y

Citation for publication: Kang Y, McCormick D, Zallman L. Affordability of and Access to Information About Health Insurance Among Immigrant and Non-immigrant Residents After Massachusetts Health Reform. J Immigrant Minority Health. 2017 Aug;19(4):929-938.

Appendix : Publication Below

Title: Affordability of and Access to Information about Health Insurance among Immigrant and Non-immigrant Residents after Massachusetts Health Reform 


\section{ABSTRACT}

\section{Background:}

Immigrants' perceptions of affordability of insurance and knowledge of insurance after health reform are unknown.

\section{Methods:}

We conducted face-to-face surveys with a convenience sample of 1,124 patients in three Massachusetts safety net Emergency Departments (EDs) after the Massachusetts health reform (August 2013-January 2014), comparing immigrants and non-immigrants.

\section{Results:}

Immigrants, as compared to non-immigrants, reported more concern about paying premiums ( $30 \% \mathrm{vs} 11 \%$, $\mathrm{p}=0.0003)$ and about affording the current ED visit ( 38 vs $22 \%$, p $<0.0001)$. Immigrants were also less likely to report having unpaid medical bills $(24$ vs $32 \%, \mathrm{p}=0.0079)$, however this difference was not present among those with any hospitalization in the past year. Insured immigrants were less likely to know copayment amounts ( $57 \mathrm{vs.} 71 \%, \mathrm{p}=0.0018$ ). Immigrants were more likely to report that signing up for insurance would be easier with fewer plans ( $53 \mathrm{vs.} \mathrm{34 \% ,} \mathrm{p}=0.0443$ ) and to lack information about insurance in their primary language ( $31 \mathrm{vs} 1 \%, \mathrm{p}<0.0001$ ) when applying for insurance. Immigrants who sought insurance information via websites or helplines were more likely to find that information useful than non-immigrants $(100 \mathrm{v} 92 \%, \mathrm{p}=0.0339)$.

Conclusions: Immigrants seeking care in safety net emergency departments had mixed experiences with affordability of and knowledge about insurance after Massachusetts health reform, raising concern about potential disparities under the Affordable Care Act that is based on the MA reform. 


\section{BACKGROUND}

Currently, 40 million immigrants reside in the U.S. [1] and by 2050, immigrants will comprise $20 \%$ of the population.[2] This large and growing population has poorer access to and outcomes of care than non-immigrants, differences that are often attributed to immigrants' high uninsurance rates.[3-5]

The 2006 Massachusetts health reform, the model for the Affordable Care Act (ACA), aimed to achieve near universal health insurance coverage and thereby increase the affordability of care and broaden healthcare access, particularly for vulnerable populations.[6] Indeed, early evidence suggests that immigrants gained access to insurance at high rates.[7] Little is known, however, about immigrants' perceptions of affordability of care or understanding of insurance after health reform. Because the ACA's main expansion provisions were implemented in January, 2014 and effects of the reform may not be realized in early years, the full impact of the ACA may not be known for several years. The Massachusetts (MA) reform, in contrast, was implemented from 2006-2007 and thus provides an opportunity to examine the impact of a similar but more mature reform on immigrants' experiences several years ahead of ACA data availability.

The Massachusetts reform had three major features affecting insurance coverage among immigrants and US-born. First, the reform required MA residents to acquire health insurance or be fined, enforced via a tax-penalty. While everyone with incomes $\geq$ $150 \%$ FPL was subject to the mandate, could apply for exemptions if they demonstrated financial hardship, had religious objections, were children, or were uninsured $<90$ days.[8,9] Second, it increased enrollment in the state's Medicaid program for legal residents who individuals met income and other eligibility requirements (pregnant women, disabled or HIV positive individuals, e.g.),[9] except that legally present immigrants in the US for $<5$ years were ineligible for Medicaid. Third, it made new subsidized insurance plans available for legal residents with incomes $<300 \%$ FPL through a newly created health insurance exchange. Both before and after the reform, immigrants lacking documentation of legal status were ineligible for public insurance 
but could receive free or reduced cost care at selected clinics and hospitals through an uncompensated care pool (called the Health Safety Net (HSN) after reform).

The Massachusetts reform reduced the uninsured rate among non-elderly adults (age 18-64) from approximately $11 \%$ in 2006 to 6\% in 2010 [9] with larger declines among racial and ethnic minorities and lower income individuals.[10] Data suggest that the reform improved access to and the affordability of care.[11-13] However, most studies examining racial and ethnic disparities in access to care failed to find narrowing of disparities. One study found improvements in having personal physicians for Hispanic compared with white residents (although among Spanish only speaking individuals, this worsened), [14] while two studies failed to find improvement in this outcome.[15, 16] One study found narrowing of racial and ethnic disparities in mortality, though this was not statistically significant. [17] Other studies found no reduction in racial and ethnic disparities in being unable to see physicians because of cost, $[15,16]$ receipt of preventive services,[16] and admissions for ambulatory care sensitive conditions, [18] a measure of access to care. No prior studies, however, have assessed access to or affordability of care among immigrants after the MA reform.

In this non-population based study, we conducted surveys in a convenience sample of emergency department (ED) users of three hospitals to assess immigrants', as compared to non-immigrants', understanding of, experiences obtaining and perceptions of affordability of insurance, as well as perceived affordability of care six years after implementation of the MA reform.

\section{METHODS}

\section{Study Design, Setting and Participants}

This study was intended to examine a highly policy relevant population - immigrants seeking health care and to compare them with non-immigrants. Thus, we queried a convenience sample of patients seeking emergency care at three safety net hospitals, settings where immigrant and non-immigrant patients commonly seek care. Our strategy allowed us to reach immigrants in a cost- 
effective manner and allowed us to focus on residents utilizing care and insurance, who could thus comment on affordability of care and insurance.

Between August 2013 and January 2014, we interviewed patients in three EDs of Massachusetts' second largest safety net institution. We included patients aged 18-64 years, the age range impacted directly by health reform, who spoke one of four languages (English, Spanish, Portuguese, or Haitian Creole), had an Emergency Severity Index (ESI)[19] of 2-5 (excluding the most severely ill ESI of 1) and were insured by only one insurer,were uninsured or were recipients of HSN. We also excluded patients with altered mental status, inability to speak, and those who reported learning of changes in insurance status or type during the interview day; while most patients accurately report if they are insured, their ability to report the source of insurance may be limited [20]. We considered patients to be immigrants if they reported being born outside of the US mainland (including Puerto Rico and Samoa); consistent with other surveys, we did not assess legal documentation status.[21, 22]

The Cambridge Health Alliance Institutional Review Board approved this study.

\section{Study Recruitment and Data Collection}

Trained research assistants identified patients, conducted informed consent and verbally surveyed patients. Bilingual research assistants or trained medical interpreters working with research assistants conducted informed consent and interviewed non-English speaking patients. Patients received \$10 gift cards for participating. Interviews were conducted daily between 9 am and $11 \mathrm{pm}$.

Survey Development and Measures 
Our survey instrument drew from other validated surveys.[12, 23, 24] We queried all participants about having a payment plan with a hospital or doctors' office, having unpaid medical bills and being unable to afford basic needs such as food, heat or rent due to medical costs; for the latter two, among insured participants and those with HSN, we asked respondents to consider medical costs for anyone insured under their plan. We inquired about affordability of insurance by determining agreement with "my insurance is affordable" and asked whether participants were worried about paying their insurance premiums. We also inquired if participants were concerned that the current ED visit may lead to payment plan or difficulty paying for food, heat or rent. Since assessments of affordability using these questions are subjective, we measure respondent's perception of affordability. However, for clarity and efficiency, we henceforth refer to this as "affordability".

We assessed understanding of insurance by inquiring about confidence in knowledge of coverage and costs among insured persons and those with HSN. We also assessed correct statement of copayment amounts for regular doctors' visits and generic medications among insured persons for whom we could verify copayment amounts (Medicaid and Commonwealth Care (CWC)). Because we could not verify copayment amounts for privately insured persons, we excluded them from these questions.

Trained medical interpreters translated the survey into Spanish, Portuguese and Haitian Creole.

Analysis

We calculated survey response frequencies among immigrants and non-immigrants, and tested for statistical significance with chi-square analyses. Because previous studies have shown that fewer immigrants require medical care due to their being healthier overall, $[25,26]$ we stratified analyses of having unpaid bills by whether or not respondents had a hospitalization in the past year.

The primary aim of this study was to assess 1. perceptions of affordability of insurance and financial concerns; and 2. challenges in understanding and applying for health insurance among immigrants and to compare these to non-immigrants. We 
were interested in understanding immigrants' actual experiences in these domains, rather than the degree to which differences between immigrants and non-immigrants were due to characteristics associated with immigration status (e.g., income or language). Thus, we did not control for demographic or clinical features in our primary analyses. A secondary aim, however, was to understand whether demographic differences, particularly insurance, helped explain immigrant-non immigrant differences. Thus, we conducted multivariable logistic regression analyses controlling for age, gender, employment, education, and income, and then subsequently added insurance and finally race/ethnicity (after confirming there was no collinearity between race/ethnicity and immigrant status) (Appendix A). Because the main types of insurance obtained under the MA health reform were publicly sponsored (Medicaid and CWC), we also examined whether immigrant vs non-immigrant differences persisted among a sample limited to these insurances (Appendix A).

In order to capture experiences obtaining health insurance under MA reform, we excluded patients who acquired insurance prior to MA reform from analyses of experiences obtaining health insurance.

To assess non-response bias, we compared demographic characteristics of respondents and non-respondents using Student's t-test and chi-square tests. All analyses were performed using SAS software version 9.4 (SAS Institute, Cary, North Carolina).

\section{RESULTS}

Eighty three percent $(1,271$ of 1,523) of potential subjects agreed to participate; we excluded 74 for whom place of birth was unknown, then excluded 4 for whom primary insurance type was unknown and finally 69 who acquired insurance after ACA open enrollment began in Oct, 2013, yielding a final sample size of 1,124. Non-respondents were more likely to have higher acuity levels (ESI scores of 2-3) (62\% vs. 53\%, respectively, $\mathrm{p}=0.010)$ and to be female (66\% vs. 58\%, respectively, 0.030). Non respondents and respondents did not differ in their insurance type or age. A greater portion of immigrants were older, female, 
Hispanic, and employed and a lower proportion completed a high school education (Table 1). Eighteen percent of immigrants were uninsured, compared with $12 \%$ of non-immigrants.

\section{Affordability of insurance and financial concerns}

Thirty-eight percent of immigrants, significantly more than among non-immigrants (22\%), were concerned about paying for their current ED visit (Table 2). Seventeen percent of immigrants were unable to afford basic needs due to medical bills and ten percent of reported setting up payment plans with a hospital or doctor's office; though these were no different than among nonimmigrants. Fewer immigrants (24\%) had unpaid medical bills as compared to the non-immigrants (32\%). However, among respondents that had a hospitalization in the past year, similar proportions reported having unpaid medical bills. Thirty percent of immigrants were concerned about paying their premiums, higher than among non-immigrants (11\%).

\section{Understanding of and experiences obtaining insurance}

Immigrants had difficulty understanding insurance; only 57\% correctly stated their copayments, fewer than among nonimmigrants (71\%), and 34\% expressed low confidence in their knowledge of coverage and costs (Table 3 ).

Thirty-seven percent of immigrants reported difficulty figuring out how to apply for insurance or difficulty completing the application process, similar to non-immigrants (39\%). Significantly more immigrants than non-immigrants (31\% vs 1\%) did not have information in their primary language when applying for insurance. More immigrants (53\%) than non-immigrants (34\%) reported that signing up for insurance would be easier with fewer plans..

Forty percent of immigrants attempted to get information from people at health centers or community-based organizations similar to the proportion among non-immigrants; nearly all reported that information obtained via this method was helpful (98\% for both groups). Though there was no difference in the proportion of immigrants (54\%) and non-immigrants (63\%) obtaining 
information through websites or telephone help-lines; when information was obtained from these sources, more immigrants (100\%) than non-immigrants $(92 \%)$ reported that information was helpful.

Secondary Analyses: Publicly insured and Multivariate logistic regression analyses

Most differences persisted in analyses limited to publicly insured persons, and a few additional differences emerged (Appendix A). In general, adjustment for socio-demographic factors including age, gender, income, education, and employment did not alter the main findings; adding insurance to these models also did not alter these findings for most outcomes. Several of these disparities for immigrants were no longer significant, after adjusting for race/ethnicity.

\section{DISCUSSION}

This is the first study to gauge perceptions of affordability of care and knowledge of insurance among immigrants under Massachusetts (MA) health reform and to compare these with non-immigrants. Among 1,124 patients seeking emergency care after MA health reform, immigrants reported more concern about paying premiums and affording the current ED visit but fewer unpaid medical bills. Immigrants reported mixed experiences with understanding and obtaining health insurance. Immigrants correctly stated their copayments a relatively low percentage of the time and few had access to information in their primary language and more reported that signing up for insurance would have been easier with fewer plans. Only about half of immigrants sought information about health insurance from websites, helplines, health centers or community organizations, but when they did, they were nearly universally likely to find the information useful. In fact, immigrants were more likely than non-immigrants to find the information obtained from websites and helplines to be useful. For many but not all of these measures of affordability and understanding of insurance, immigrants fared worse than non-immigrants. 
Because our study lacks a pre-reform baseline and a control group outside of the state, our findings do not shed light on the extent to which the MA reform may have decreased (or not decreased) disparities between immigrants and non-immigrants. Rather, the study focuses on a description of disparities present in the post-reform era.

Although affordability difficulties were more common among immigrants for some measures, it is notable that having unpaid medical bills were less common. However, as in other studies, immigrants had fewer hospitalizations that may necessitate health care expenditures.[27-29] After stratifying by hospitalizations, immigrants and non-immigrants who had hospitalizations had similar rates of unpaid medical bills. This observation suggests that lower levels of unpaid medical bills among immigrants was largely due to their having less need for care such as hospitalizations. It also highlights that in some measures of affordability of care, disparities were not present.

The reasons for greater proportions of immigrants experiencing difficulties affording insurance compared with nonimmigrants, where they existed, are likely to be multifactorial. Many MA residents purchased private insurance to comply with the individual mandate and many low to moderate income residents obtained public insurance. However, immigrants lacking documentation of legal residence were ineligible for public insurance and many were likely not offered or unable to afford employer-sponsored private insurance. [3] The higher rate of uninsurance among immigrants likely contributed to greater levels of difficulty affording insurance among immigrants. However, insurance status and type did not appear to explain a large percentage of immigrant vs non-immigrant differences in affordability measures, as disparities persisted in multivariate models controlling for insurance and in analyses restricted to the publicly insured. This last observation suggests that even under public insurance plans that formed the bulk of newly obtained insurance under the reform,[30] affordability challenges for immigrants existed.

Although demographic characteristics of immigrants and non-immigrants commonly underlie differences in access and health utilization between these groups,[31,32] controlling for factors such as age, gender, income, education, and unemployment status in multivariable models largely did not substantially influence our results, suggesting that these were not major explanatory factors. However, several disparities appeared to be influenced to some degree by race/ethnicity in addition to immigration status. 
Immigrants may express higher concerns about affordability for several reasons. In our study, immigrants demonstrated lower levels of understanding about their insurance; this lower level of understanding may have led to increased uncertainty about and therefore more concern about how much the current ED visit would cost. Although we did not find a difference in income between immigrants and non-immigrants, immigrants may experience less job security and may work in jobs with less reliable income streams (e.g. as day laborers), leading to a less stable cash flow to pay for premiums. Immigrants may also have higher economic burdens for factors such as remittances to family members in home countries,[33] leading to less available income. The full scope of underlying reasons for continued difficulty affording care among immigrants merits further research.

Immigrants reported mixed experiences with obtaining and understanding insurance as compared to non-immigrants. The fact that immigrants were more likely to find information obtained via websites or helplines (and equally likely to find information obtained from people in health centers or community based organizations) to be useful points to well-targeted consumer support; in fact, among immigrants, $100 \%$ of website and helpline users and $98 \%$ of health center and community based organization users found this information helpful. At the same time, immigrants were less likely to understand their copayments and more likely to report that signing up for insurance would have been easier with fewer plans, suggesting that greater outreach to immigrants who are eligible to receive public insurance may need to augment the considerable outreach efforts made under the Massachusetts reform. [34, 35] Our findings may also imply that employers offering insurance plans and insurance companies need to better provide plan information tailored to immigrant populations. For example, thirty-one percent of immigrants lacked information in their primary language when acquiring insurance. While non-English information about government-sponsored insurances was available,[36] immigrants may have spoken other languages or may not have known of this information. Further efforts to improve immigrants' exposure to information in non-English languages may improve their experience with insurance.

This study was intended to query a population of high policy relevance and was not designed as a population-based study. Our setting and inclusion criteria sampled a population that is different than the general population (who likely have different acuity, more ED visits, and less outpatient access); this may have led to over-representation of persons with difficulty affording 
care. While these characteristics may lead to overrepresentation of affordability problems (among both immigrants and non-

immigrants), they are unlikely to affect comparisons between these groups. Because it is a convenience sample, our results are not representative of the general MA population. For example, although our sample was $58 \%$ female, statewide, females are $52 \%$ of the population.[37] Also, patient perceptions of affordability of insurance may not reflect actual affordability defined in objective terms (e.g., health care spending exceeding a defined percentage of income). As is common among survey data, our income data had missing values (10\%) and values that may reveal inaccurate reporting (such as a value of \$1).

The extent to which our findings are applicable to the ACA is an important policy question. The MA health reform placed fewer restrictions on immigrant eligibility for publicly sponsored insurance than the ACA. The MA reform provided state subsidized private insurance plans (to those with incomes $\leq 300 \%$ FPL) called Commonwealth Care (CWC) to legally present immigrants in the US $<5$ years who were ineligible for federally sponsored health insurance. [38, 39] As part of the reform, MA also created the Health Safety Net Fund that paid for essential health services for the uninsured and underinsured, including undocumented and legally present immigrants who met income eligibility requirements.[40, 41] The ACA, does, however, provide substantial funding for outreach and navigation and extends eligibility for publicly subsidized private insurance for legally present immigrants to $400 \%$ FPL, as compared to $300 \%$ FPL under the MA reform. The extent to which challenges we identified for immigrants after the MA reform will be seen under the ACA is difficult to estimate but our findings should raise concern that immigrants may be continuing to face substantial barriers to affording and understanding insurance and affording health care under the ACA. Our study points to the need for careful monitoring of and likely additional provisions - such as improved access to subsidized and low cost insurance - to reduce disparities and improve immigrants' experiences affording care. 


\section{References}

1. PEW Hispanic Research Center. A Nation of Immigrants: A Portrait of the 40 Million, Including 11 Million Unauthorized. [cited 7/28/15]; Available from: http://www.pewhispanic.org/2013/01/29/a-nation-of-immigrants/

2. Passel JS and Cohn DV. U.S. population projections: 2005-2050. 2008 [cited 7/28/16]; Available from: http://www.pewhispanic.org/2008/02/11/us-population-projections-2005-2050/.

3. Ku L and Matani S, Left out: immigrants' access to health care and insurance. . Health Aff (Millwood), 2001. 20(1): p. 247256.

4. Perez-Escamilla R, Garcia J, and Song D, Health Care Access among Hispanic Immigrants: Alguien esta escuchando? [Is anybody listening?] NAPA Bull, 2010. 34(1): p. 47-67.

5. Rodriguez MA, Bustamante AV, and Ang A, Perceived quality of care, receipt of preventive care, and usual source of health care among undocumented and other Latinos. J Gen Intern Med, 2009. 24 Suppl 2: p. 508-513.

6. Chapter 58: An Act Providing Access to Affordable, Quality, Accountable Health Care. 2006 [cited 7/28/16]; Available from: http://www.mass.gov/legis/laws/seslaw06/sl060058.htm.

7. Sabrina Tavernise and R. Gebeloff, Immigrants, the Poor and Minorities Gain Sharply Under Affordable Care Act, in The New York Times. 2016.

8. Linda J. Blumberg and L. Clemans-Cope, Reconciling the Massachusetts and Federal Individual Mandates for health insurance: a comparison of policy Options. 2012, Blue Cross Blue Shield Foundation of Massachusetts.

9. The Kaiser Family Foundation. Massachusetts Health Care Reform: Six Years Later 2012 [cited 7/28/16]; Available from: https://kaiserfamilyfoundation.files.wordpress.com/2013/01/8311.pdf.

10. Kolstad JT and K. AE, The impact of health care reform on hospital and preventive care: evidence from Massachusetts (Working Paper 16012). 2010, National Bureau of Economic Research.

11. Van der Wees, P.J., et al., Governing healthcare through performance measurement in Massachusetts and the Netherlands. Health Policy, 2014. 116(1): p. 18-26.

12. Long SK, Triplett T, and Dutwin D. The Massachusetts Health Reform Survey 2012 [cited Feb 28, 2015]; Available from: http://www.urban.org/UploadedPDF/411649 mass reform survey.pdf.

13. Pande, A.H., et al., Effects of healthcare reforms on coverage, access, and disparities: quasi-experimental analysis of evidence from Massachusetts. American Journal of Preventive Medicine, 2011. 41(1): p. 1-8.

14. Maxwell, J., et al., Massachusetts' Health Care Reform Increased Access To Care For Hispanics, But Disparities Remain. Health Affairs, 2011. 30(8): p. 1451-1460. 
15. Zhu, J., et al., Massachusetts health reform and disparities in coverage, access and health status. J Gen Intern Med, 2010. 25(12): p. 1356-62.

16. Van Der Wees, P.J., A.M. Zaslavsky, and J.Z. Ayanian, Improvements in health status after Massachusetts health care reform. Milbank Q, 2013. 91(4): p. 663-89.

17. Sommers, B.D., S.K. Long, and K. Baicker, Changes in mortality after Massachusetts health care reform: a quasiexperimental study. Ann Intern Med, 2014. 160(9): p. 585-93.

18. McCormick, D., et al., Effect of Massachusetts healthcare reform on racial and ethnic disparities in admissions to hospital for ambulatory care sensitive conditions: retrospective analysis of hospital episode statistics. Bmj, 2015. 350: p. h1480.

19. Agency for Healthcare Research and Quality. Emergency Severity Index (ESI): A Triage Tool for Emergency Department: DVDs and 2012 Edition of the Implementation Handbook. February 2013 [cited 7/28/16]; Available from: http://www.ahrq.gov/professionals/systems/hospital/esi/index.html.

20. Nelson, D.E., et al., What people really know about their health insurance: a comparison of information obtained from individuals and their insurers. Am J Public Health, 2000. 90(6): p. 924-8.

21. Agency for Healthcare Research and Quality. US Department of Health and Human Services. Medical Expenditure Panel Survey. [cited 7/28/16]; Available from: http://meps.ahrq.gov/survey comp/survey.jsp.

22. CDC/National Center for Health Statistics. National Health and Nutrition Examination Survey. [cited 7/28/16]; Available from: http://www.cdc.gov/nchs/nhanes/nhanes questionnaires.htm.

23. Galbraith AA, et al., Some families who purchased health coverage through the Massachusetts Connector wound up with high financial burdens. Health Aff (Millwood), 2013. 32(5): p. 974-83.

24. Sinaiko, A.D., et al., The Experience Of Massachusetts Shows That Consumers Will Need Help In Navigating Insurance Exchanges. Health Affairs, 2013. 32(1): p. 78-86.

25. Corlin, L., et al., Evidence for the healthy immigrant effect in older Chinese immigrants: a cross-sectional study. BMC Public Health. 14: p. 603.

26. Singh, G.K. and M. Siahpush, All-cause and cause-specific mortality of immigrants and native born in the United States. Am J Public Health, 2001. 91(3): p. 392-9.

27. Stimpson, J.P., F.A. Wilson, and D. Su, Unauthorized immigrants spend less than other immigrants and US natives on health care. Health Aff (Millwood), 2013. 32(7): p. 1313-8.

28. Stimpson, J.P., F.A. Wilson, and K. Eschbach, Trends in health care spending for immigrants in the United States. Health Aff (Millwood), 2010. 29(3): p. 544-50.

29. Muennig, P. and M.C. Fahs, Health status and hospital utilization of recent immigrants to New York City. Prev Med, 2002. 35(3): p. 225-31. 
30. Massachusetts Health Connector. Health Reform Facts and Figures: Fall 2012. 2012 [cited 7/28/16]; Available from: https://betterhealthconnector.com/wp-content/uploads/reports-and-publications/FactsandFigures.pdf.

31. Borrell, L.N., et al., Black/white disparity in self-reported hypertension: the role of nativity status. J Health Care Poor Underserved, 2008. 19(4): p. 1148-62.

32. Goel, M.S., et al., Racial and ethnic disparities in cancer screening: the importance of foreign birth as a barrier to care. J Gen Intern Med, 2003. 18(12): p. 1028-35.

33. Congressional Budget Office. Remittances: International Payments by Migrants. 2005 [cited April 29, 2015]; Available from: http://www.cbo.gov/sites/default/files/cbofiles/ftpdocs/63xx/doc6366/05-19-remittances.pdf.

34. Raymond, A.G., Lessons from the Implementation of Massachusetts Health Reform. 2011, Blue Cross Blue Shield of Massachusetts Foundation. p. 4-22.

35. Sabrina Corlette, et al. The Massachusetts and Utah Health Insurance Exchanges: Lessons Learned. [cited 7/28/16]; Available from: http://ccf.georgetown.edu/wp-content/uploads/2012/03/Health-reform exchanges.pdf.

36. Massachusetts Health Connector Language Support [cited Feb 28, 2015]; Available from: https://www.mahealthconnector.org/language-support.

37. A Profile of Health Among Massachusetts Adults, 2013. Results from the Behavioral Risk Factor Surveillance System. [cited 7/28/16]; Available from: http://www.mass.gov/eohhs/docs/dph/behavioral-risk/report-2013.pdf.

38. HealthConnector Commonwealth Care, Commonwealth Care Program Guide. 2012.

39. Massachusetts Law Reform Institute and MetroWest Legal Services. A Legal Aid Primer Constituent Questions on Commonwealth Care. Massachusetts Legal Assistance Corporation. [cited April 2, 2015]; Available from: http://jimwelch.com/sites/jimwelch.com/files/ma legal assistance corp - qa on commnwealth care.pdf.

40. Cunha GA. Ongoing Analysis of the Health Safety Net Trust Fund: MassHealth's New Prepayment Obligations. Office of the Inspector General, Commonwealth of Massachusetts. . 2014 [cited Mar 1, 2013]; Available from:

http://www.mass.gov/ig/publications/reports-and-recommendations/2013/health-safety-net-march-2013.pdf.

41. Massachusetts State Executive Office of Health and Human Services (EOHHS). [cited 7/28/16]; Available from: http://www.mass.gov/eohhs/consumer/insurance/more-programs/health-safety-net/for-patients.html. 


\begin{tabular}{|c|c|c|c|}
\hline & $\begin{array}{c}\text { Immigrant } \\
\mathrm{N}=480 \\
\%\end{array}$ & $\begin{array}{c}\text { US- born } \\
\mathrm{N}=644 \\
\%\end{array}$ & $P$ value \\
\hline Male & 37 & 46 & 0.0058 \\
\hline Completed at least a High School Degree & 82 & 88 & 0.0040 \\
\hline Primary Insurance Type & & & $<\mathbf{0 . 0 0 0 1}$ \\
\hline Uninsured & 18 & 12 & \\
\hline Health Safety Net ${ }^{\#}$ & 20 & 2 & \\
\hline 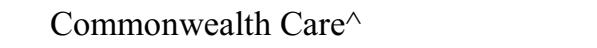 & 13 & 10 & \\
\hline Medicaid & 34 & 44 & \\
\hline Private & 15 & 31 & \\
\hline Race & & & $<0.0001$ \\
\hline Black, non-Hispanic & 18 & 12 & \\
\hline White, non-Hispanic & 11 & 65 & \\
\hline Hispanic & 56 & 16 & \\
\hline Other, non-Hispanic & 14 & 8 & \\
\hline Age & & & $<0.0001$ \\
\hline $18-30$ & 31 & 44 & \\
\hline $31-45$ & 43 & 31 & \\
\hline $46-65$ & 26 & 25 & \\
\hline Annual Income $<=\$ 20,000$ & 56 & 58 & 0.5398 \\
\hline Employed & 69 & 61 & 0.0035 \\
\hline Emergency Severity Index & & & 0.8929 \\
\hline 2 or 3 & 52 & 53 & \\
\hline 4 or 5 & 48 & 47 & \\
\hline Any prescription since on insurance plan & 76 & 78 & 0.4760 \\
\hline No doctors visits in past year & 14 & 18 & 0.1152 \\
\hline
\end{tabular}




\begin{tabular}{|l|c|c|c|}
\hline $\begin{array}{l}\text { Hospitalization past year, excluding } \\
\text { reason of giving birth }\end{array}$ & 18 & 23 & 0.0817 \\
\hline Excellent or very good health status & 39 & 35 & 0.1730 \\
\hline
\end{tabular}

*p values less than 0.05 are bolded

\# Health Safety Net is a program for Massachusetts residents who are not eligible for health insurance or can't afford to buy it. It pays for medically necessary services at Massachusetts community health centers (CHCs) and hospitals.

${ }^{\wedge}$ Commonwealth Care is a private insurance that was publicly subsidized for residents with incomes below $300 \%$ of the federal poverty level under

Massachusetts health reform.

\begin{tabular}{|c|c|c|c|}
\hline & $\begin{array}{c}\text { Immigrant } \\
\mathrm{N}=480 \\
\% \\
\end{array}$ & $\begin{array}{c}\text { US- born } \\
\mathrm{N}=644 \\
\% \\
\end{array}$ & $P$ value \\
\hline \multicolumn{4}{|l|}{ Financial concerns } \\
\hline Has unpaid medical bills & 24 & 32 & 0.0079 \\
\hline Hospitalization in past year & 37 & 34 & 0.6697 \\
\hline No Hospitalization in past year & 22 & 31 & 0.0018 \\
\hline Has payment plan with hospital or doctor's office & 10 & 8 & 0.1774 \\
\hline Cannot afford basic needs due to medical bills & 17 & 13 & 0.0651 \\
\hline $\begin{array}{l}\text { Concerned about affording the current emergency } \\
\text { department visit }\end{array}$ & 38 & 22 & $<0.0001$ \\
\hline \multicolumn{4}{|l|}{ Affordability of insurance, among insured } \\
\hline Disagrees that insurance is affordable ${ }^{@}$ & 12 & 9 & 0.1566 \\
\hline Worried about paying any premium & 30 & 11 & 0.0003 \\
\hline
\end{tabular}

$* p$ values less than 0.05 are bolded

@Includes participants covered by Health Safety Net, which had had no premium 


\begin{tabular}{|c|c|c|c|}
\hline & $\begin{array}{c}\text { Immigrant } \\
\mathrm{N}=350 \\
\% \\
\end{array}$ & $\begin{array}{c}\text { US- born } \\
\mathrm{N}=224 \\
\% \\
\end{array}$ & P value \\
\hline \multicolumn{4}{|l|}{ Understanding of insurance } \\
\hline Correctly stated copayment for PCP visit and medication*^ & 57 & 71 & 0.0018 \\
\hline Not confident in knowledge of coverage and costs & 34 & 32 & 0.3827 \\
\hline \multicolumn{4}{|c|}{ Experiences applying for insurance, among those who had a role in application process } \\
\hline $\begin{array}{l}\text { Difficult to figure out how to apply for insurance or complete } \\
\text { application process }\end{array}$ & 37 & 39 & 0.8431 \\
\hline Did not have information in primary language & 31 & 1 & $<0.0001$ \\
\hline Attempted to get information through websites or helpline & 54 & 63 & 0.1289 \\
\hline $\begin{array}{l}\text { Website or helpline information to find insurance was } \\
\text { helpful }\end{array}$ & 100 & 92 & 0.0339 \\
\hline $\begin{array}{l}\text { Attempted to get information from person at health center or } \\
\text { from community-based organization }\end{array}$ & 40 & 30 & 0.0898 \\
\hline $\begin{array}{l}\text { Information from person at health center or from } \\
\text { community-based organization was helpful }\end{array}$ & 98 & 98 & 0.8663 \\
\hline Signing up for insurance would be easier with fewer plans \# & 53 & 34 & 0.0443 \\
\hline
\end{tabular}

${ }^{\circ} \mathrm{p}$ values less than 0.05 are bolded

${ }^{\circledR}$ Includes insured participants and those covered by Health Safety Net

* limited to participants with government sponsored insurance because could not verify copayments for the privately insured.Does not include HSN

$\wedge$ named correct range nearest dollar

\# among those who had a role in choosing their insurance 


\begin{tabular}{|c|c|c|c|}
\hline \multicolumn{4}{|c|}{$\begin{array}{l}\text { Appendix Table 1. Perceived affordability of insurance and medical care among publicly insured (Medicaid } \\
\text { or Commonwealth Care) individuals * }\end{array}$} \\
\hline & $\begin{array}{c}\text { Immigrant } \\
\mathrm{N}=350 \\
\%\end{array}$ & $\begin{array}{c}\text { US- born } \\
\mathrm{N}=224 \\
\%\end{array}$ & P value \\
\hline \multicolumn{4}{|l|}{ Financial concerns } \\
\hline Has unpaid medical bills & 23 & 24 & 0.8121 \\
\hline Hospitalization in past year & 38 & 25 & 0.1391 \\
\hline No Hospitalization in past year & 20 & 24 & 0.3687 \\
\hline Has payment plan with hospital or doctor's office & 10 & 5 & 0.0235 \\
\hline Cannot afford basic needs due to medical bills & 17 & 12 & 0.1155 \\
\hline $\begin{array}{l}\text { Concerned about affording the current emergency } \\
\text { department visit }\end{array}$ & 33 & 13 & $<0.0001$ \\
\hline \multicolumn{4}{|l|}{ Affordability of insurance, among insured } \\
\hline Disagrees that insurance is affordable & 10 & 4 & 0.0082 \\
\hline Worried about paying any premium & 46 & 15 & 0.0228 \\
\hline
\end{tabular}

*p values less than 0.05 are bolded 


\begin{tabular}{|c|c|c|c|}
\hline \multicolumn{4}{|c|}{$\begin{array}{l}\text { Appendix Table 2. Understanding of insurance and experiences obtaining insurance among publicly insured } \\
\text { (Medicaid or Commonwealth Care) individuals \% }\end{array}$} \\
\hline & $\begin{array}{c}\text { Immigrant } \\
\mathrm{N}=350 \\
\%\end{array}$ & $\begin{array}{c}\text { US- born } \\
\mathrm{N}=224 \\
\%\end{array}$ & P value \\
\hline \multicolumn{4}{|l|}{ Understanding of insurance } \\
\hline Correctly stated copayment for PCP visit and medication*^ & 57 & 71 & 0.0018 \\
\hline Not confident in knowledge of coverage and costs & 36 & 23 & 0.0007 \\
\hline \multicolumn{4}{|c|}{ Experiences applying for insurance, among those who had a role in application process } \\
\hline $\begin{array}{l}\text { Difficult to figure out how to apply for insurance or complete } \\
\text { application process }\end{array}$ & 40 & 47 & 0.2785 \\
\hline Did not have information in primary language & 33 & 1 & $<0.0001$ \\
\hline Attempted to get information through websites or helpline & 55 & 70 & 0.0192 \\
\hline $\begin{array}{l}\text { Website or helpline information to find insurance was } \\
\text { helpful }\end{array}$ & 100 & 91 & 0.0347 \\
\hline $\begin{array}{l}\text { Attempted to get information from person at health center or } \\
\text { from community-based organization }\end{array}$ & 46 & 36 & 0.1330 \\
\hline $\begin{array}{l}\text { Information from person at health center or from } \\
\text { community-based organization was helpful }\end{array}$ & 98 & 100 & 0.2709 \\
\hline Signing up for insurance would be easier with fewer plans ${ }^{\#}$ & 45 & 42 & 0.8041 \\
\hline
\end{tabular}

$\% p$ values less than 0.05 are bolded

* limited to participants with government sponsored insurance because could not verify copayments for the privately insured.

$\wedge$ named correct range nearest dollar

\# among those who had a role in choosing their insurance 
*Model 1 controls for age, gender, employment (employed/not employed), education (less than high school/high school or greater) and income (less than

\begin{tabular}{|c|c|c|c|c|}
\hline & $\begin{array}{l}\text { Unadjusted } \\
\text { Immigrant vs. non- } \\
\text { immigrant } \\
\text { OR (95\%CI) }\end{array}$ & $\begin{array}{c}\text { Model } 1 \\
\text { Immigrant vs. non- } \\
\text { immigrant } \\
\text { OR }(95 \% \mathrm{CI})\end{array}$ & $\begin{array}{c}\text { Model } 2 \\
\text { Immigrant vs. non- } \\
\text { immigrant } \\
\text { OR }(95 \% \mathrm{CI})\end{array}$ & $\begin{array}{c}\text { Model } 3 \\
\text { Immigrant vs. non- } \\
\text { immigrant } \\
\text { OR (95\%CI) }\end{array}$ \\
\hline \multicolumn{5}{|l|}{ Financial Concerns } \\
\hline Has unpaid medical bills & $0.69(0.53-0.91)$ & $0.71(0.53-0.96)$ & $0.67(0.49-0.92)$ & $0.53(0.37-0.77)$ \\
\hline Has payment plan with hospital or doctor's office & $1.34(0.87-2.06)$ & $1.25(0.78-1.99)$ & $1.14(0.69-1.88)$ & $1.45(0.79-2.65)$ \\
\hline Cannot afford basic needs due to medical bills & $1.39(0.98-1.97)$ & $1.53(1.05-2.23)$ & $1.48(0.99-2.21)$ & $1.30(0.82-2.07)$ \\
\hline $\begin{array}{l}\text { Concerned about affording the current emergency } \\
\text { department visit }\end{array}$ & $2.14(1.63-2.82)$ & $2.13(1.58-2.86)$ & $1.83(1.33-2.54)$ & $1.78(1.21-2.62)$ \\
\hline \multicolumn{5}{|l|}{ Affordability of insurance, among insured } \\
\hline Disagrees that insurance is affordable ${ }^{@}$ & $1.37(0.89-2.12)$ & $1.31(0.82-2.11)$ & $2.13(1.27-3.56)$ & $1.75(0.93-3.30)$ \\
\hline Worried about paying any premium & $3.41(1.73-6.73)$ & $3.53(1.59-7.83)$ & $3.32(1.45-7.58)$ & $2.29(0.77-6.80)$ \\
\hline
\end{tabular}

*Model 1 controls for age, gender, employment (employed/not employed), education (less than high school/high school or greater) and income (\$20 K or less than $\$ 20 \mathrm{~K}$ annually/more than $\$ 20 \mathrm{~K}$ annually); Model 2 controls for all factors in Model 1 and insurance (Self Pay, Health Safety Net, Publicly Insured,

Privately Insured) Model 3 controls for all factors in Model 2 and race/ethnicity (White non Hispanic, Black non Hispanic, Hispanic, and Other non Hispanic)

${ }^{\circledR}$ Includes participants covered by Health Safety Net, which had had no premium 


\begin{tabular}{|c|c|c|c|c|}
\hline \multicolumn{4}{|c|}{$\begin{array}{l}\text { Appendix Table 4. Understanding of insurance and experiences obtaining insurance, controlling for demographic factors } \\
\text { and insurance* @ }\end{array}$} & \multirow[b]{2}{*}{$\begin{array}{c}\text { Model } 3 \\
\text { Immigrant vs. non- } \\
\text { immigrant } \\
\text { OR }(95 \% C I)\end{array}$} \\
\hline & $\begin{array}{c}\text { Unadjusted } \\
\text { Immigrant vs. non- } \\
\text { immigrant } \\
\text { OR }(95 \% \mathrm{CI})\end{array}$ & $\begin{array}{c}\text { Model } 1 \\
\text { Immigrant vs. non- } \\
\text { immigrant } \\
\text { OR }(95 \% \mathrm{CI})\end{array}$ & $\begin{array}{c}\text { Model } 2 \\
\text { Immigrant vs. non- } \\
\text { immigrant } \\
\text { OR }(95 \% \mathrm{CI})\end{array}$ & \\
\hline \multicolumn{5}{|l|}{ Understanding of insurance } \\
\hline $\begin{array}{l}\text { Correctly stated copayment for PCP visit and } \\
\text { medication } \& \wedge\end{array}$ & $0.54(0.37-0.80)$ & $0.61(0.39-0.95)$ & $0.62(0.39-0.97)$ & $0.44(0.25-0.78)$ \\
\hline Not confident in knowledge of coverage and costs & $1.14(0.85-1.54)$ & $1.31(0.94-1.83)$ & $1.44(1.02-2.03)$ & $1.27(0.84-1.91)$ \\
\hline \multicolumn{5}{|c|}{ Experiences applying for insurance, among those who had a role in application process $* *$} \\
\hline $\begin{array}{l}\text { Difficult to figure out how to apply for insurance or } \\
\text { complete application process }\end{array}$ & $0.95(0.60-1.52)$ & $1.01(0.60-1.68)$ & $0.91(0.53-1.54)$ & $1.38(0.72-2.65)$ \\
\hline $\begin{array}{l}\text { Attempted to get information through websites or } \\
\text { helpline }\end{array}$ & $0.69(0.43-1.12)$ & $0.579(0.337-0.998)$ & $0.55(0.31-0.96)$ & $0.56(0.28-1.11)$ \\
\hline $\begin{array}{l}\text { Attempted to get information from person at health } \\
\text { center or from community-based organization }\end{array}$ & $1.50(0.94-2.40)$ & $1.54(0.91-2.60)$ & $1.40(0.81-2.42)$ & $1.49(0.77-2.88)$ \\
\hline $\begin{array}{l}\text { Signing up for insurance would be easier with fewer } \\
\text { plans } \#\end{array}$ & $2.12(1.01-4.43)$ & $2.30(1.01-5.28)$ & $2.48(1.06-5.77)$ & $1.50(0.52-4.34)$ \\
\hline
\end{tabular}

*Model 1 controls for age, gender, employment (employed/not employed), education (less than high school/high school or greater) and income (\$20K or less than $\$ 20 \mathrm{~K}$ annually/more than $\$ 20 \mathrm{~K}$ annually); Model 2 controls for all factors in Model 1 and insurance (Self Pay, Health Safety Net, Publicly Insured, Privately Insured); Model 3 controls for all factors in Model 2 and race/ethnicity (White non Hispanic, Black non Hispanic, Hispanic, and Other non Hispanic).

\&limited to participants with government sponsored insurance because could not verify copayments for the privately insured.Does not include HSN

${ }^{\wedge}$ named correct range nearest dollar

\# among those who had a role in choosing their insurance

@ Includes insured participants and those covered by Health Safety Net

**Unable to run models for "Did not have information in primary language", "website or helpline information to find insurance was helpful" and

"information from person at health center or from community-based organization was helpful" due to too few observations in some cells or overfit models. 
